\title{
Analysis of Electromagnetic Force on Rotor End Windings of a 300 MW Variable-Speed Generator Motor for Pumped Storage
}

\author{
Zhaowei Qiao (i) and Yutian Sun \\ State Key Laboratory of Hydro-Power Equipment (HILEM), Harbin 150040, China \\ Correspondence should be addressed to Zhaowei Qiao; hec_sjsf43@163.com
}

Received 27 September 2019; Revised 31 March 2020; Accepted 21 April 2020; Published 5 May 2020

Academic Editor: Nhon Nguyen-Thanh

Copyright (C) 2020 Zhaowei Qiao and Yutian Sun. This is an open access article distributed under the Creative Commons Attribution License, which permits unrestricted use, distribution, and reproduction in any medium, provided the original work is properly cited.

\begin{abstract}
The variable-speed generator motor (VSGM) for pumped storage has a cylindrical rotor with three-phase lap or wave windings distributed in slots evenly and fed by a converter. For a large-scale VSGM, the electromagnetic force (EMF) on rotor end windings is an important contributor to distortion, vibration, and even damage of rotor end windings. A 3D finite element model of rotor end region of a $300 \mathrm{MW}$ VSGM is set up. The distribution map of EMF density on involute and nose parts of rotor end windings, under rated load and three-phase short circuit at supersynchronous and subsynchronous speed, is drawn. Furthermore, the amplitude of EMF is calculated, and the radial, tangential, and axial components of EMF are analyzed. The results in this paper will lay a foundation for design of rotor end windings and their support structure.
\end{abstract}

\section{Introduction}

Variable-speed generator motor (VSGM) has been preferred in pumped storage units since the early 1980 s $[1,2]$. Different from fixed speed generator motor (FSGM), the rotor winding of VSGM is a double-layer winding which is excited by alternating current and distributed evenly in rotor slots. Variable-speed generator motor (VSGM) for pumped storage can offer many advantages, both to the power system and to the hydropower station, as follows: (1) Balance the load of the power system by adjusting pumping power and hence contributing to frequency regulation [3]. (2) Provide grid supports in disturbances by injecting instantaneous power to the grid and hence contributing to spinning reserve reduction [4]. (3) Control the active and reactive power of grid as desired and independently of each other to satisfy the demands of the grid [5]. (4) The speed variation is about $10 \%$, which corresponds to a power variation of $30 \%[6,7]$. (5) Optimize the hydraulic performance even in the case of large head and discharge variation, which allows a great hydraulic efficiency improvement. In addition, hazardous operating zones can be avoided and variation and cavitation problems can be reduced. (6) Additional equipment for pumping startup, such as frequency converters feeding stator winding or another hydropower unit for back-to-back starting, is no need. (7) The power of frequency converter is not a full-rated power but a slip power, which makes the size of the converter small considerably.

For a large-scale VSGM, the rotor winding consists of Roebel bar and its end part is divided into three parts: the line part outside the slot, the involute part, and the nose part, which is similar to the structure of stator winding. During operation, the electromagnetic force (EMF) is produced on end windings due to interaction between currents and electromagnetic fields, which will cause vibration and deformation of end windings. Especially under the shortcircuit condition, large short-circuit current will produce strong EMF, causing fatigue and damage of end windings and shortening the life of rotor windings.

The analysis of EMF on rotor end windings of VSGM is crucial to design of rotor end windings and their support structure. Recently, the analysis and calculation of EMF on rotor end windings of VSGM have not been presented in paper, which mainly focus on stator end windings of turbo generator. Due to the structural similarity between rotor winding and stator winding, these methods can be used for 
reference. In [8, 9], a three-dimensional (3D) electromagnetic model of the stator end region of a $600 \mathrm{MW}$ turbo generator was set up to calculate EMF under rated steadystate and fault conditions, and a 3D mechanical model was built to analyze displacements using the EMF as an input. Kim et al. calculated the EMF on stator end windings of a $900 \mathrm{~kW}, 6.6 \mathrm{kV}, 4$-pole high-voltage induction motor and analyzed the distribution of EMF by segmenting one end winding with 39 parts [10]. A 3D finite element analysis of magnetic forces on stator end windings of a $1250 \mathrm{~kW}$, 6-pole squirrel-cage induction machine was carried out in [11] by using a 1/12 machine model. Albanese et al. proposed a 3D numerical calculation of EMF on the end windings of large turbo generators [12], based on an integral formulation for nonlinear magnetostatic problems. In [13], a 3D electromagnetic model of the end region of a $600 \mathrm{MW}, 2$-pole turbo-generator was set up, the EMF and deformation of stator end windings under rated load and three-phase short circuit were analyzed, and furthermore, based on [14], the influence of structural and material parameters of the end winding on its dynamic responses was investigated, and an optimal scheme for the design of the turbo generator stator end winding was proposed. A $1550 \mathrm{MW}$ nuclear generator was focused in $[15,16]$, and phase A of stator winding was selected to analyze EMF, due to the symmetry of the generator. The EMF on involute and nose parts of stator end winding under a rated operation was calculated in [15], and the influence of the rotor's relative length and stator coil's linear length on EMF was summarized. In [16], the EMF on the involute part at both rated and leading phase operation was discussed in detail. A comprehensive analysis on the transient EMF of stator windings of a QFSN-600-2YHG type turbo generator was presented in [17], which investigated not only the distribution regularities of EMF and EMF density but also EMF harmonic characteristics and the mechanical responses.

This paper presents a 3D electromagnetic model of the end region of a $300 \mathrm{MW}$ VSGM. The electromagnetic force on rotor end windings is investigated, under rated load and three-phase short circuit at supersynchronous and subsynchronous speed. The distribution regularities of EMF density on involute and nose parts of rotor end windings are predicted, and furthermore, the amplitude of EMF is calculated and the variation of radial, tangential, and axial components of EMF is discussed. Conclusions that can be beneficial for the design of rotor end windings and their support structure are drawn.

\section{Analysis of EMF on Rotor End Windings under Rated Load}

2.1.3D Electromagnetic Model. A 300 MW VSGM is studied, and its parameters are listed in Table 1. Due to the structural symmetry, the $3 \mathrm{D}$ electromagnetic model is only $1 / 7$ (one pole-pair) of the end region, which can also save the calculating memory, as shown in Figure 1.

During investigation, the subsynchronous speed is set to $407.17 \mathrm{r} / \mathrm{min}$ (i.e., negative slip is $\pm 5 \%$ ) and the supersynchronous speed is set to $450.03 \mathrm{r} / \mathrm{min}$ (i.e., positive slip is 5\%).
TABle 1: Specification of the analysis model.

\begin{tabular}{lcc}
\hline Item & Specification & Unit \\
\hline Rated apparent output & 333.3 & $\mathrm{MVA}$ \\
Rated voltage & 15.75 & $\mathrm{kV}$ \\
Rated power factor & 0.9 & \\
Rated frequency & 50 & $\mathrm{~Hz}$ \\
Rated speed & 428.6 & $\mathrm{r} / \mathrm{min}$ \\
Speed range & \pm 5 & $\%$ \\
Number of poles & 14 & \\
Flywheel moment & 5700 & $\mathrm{t} \cdot \mathrm{m}^{2}$ \\
Stator core outer diameter & 6830 & $\mathrm{~mm}$ \\
Stator core inner diameter & 5640 & $\mathrm{~mm}$ \\
Air-gap width & 20 & $\mathrm{~mm}$ \\
Number of stator slots & 357 & \\
Number of rotor slots & 231 & \\
Stator winding pitch & 22 & \\
Rotor winding pitch & 14 & \\
\hline
\end{tabular}

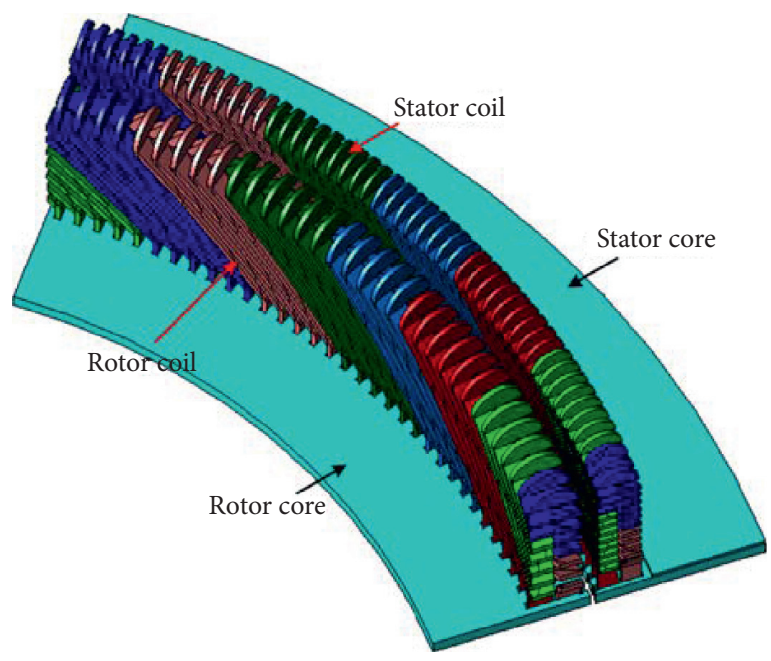

FIgURe 1: 3D electromagnetic model with one pole pair.

The short-circuit current factor (the ratio between maximum peak value of short-circuit current and peak value of rated current) is 13.69 at subsynchronous speed and 13.46 at supersynchronous speed.

2.2. At Subsynchronous Speed. Figure 2 is the distribution of magnetic flux density on the end region, which shows that the maximum value is $0.1468 \mathrm{~T}$.

Figure 3 is the distribution of EMF density on rotor end windings of $U$ phase.

As can be seen, the maximum EMF density is on the nose part of rotor end windings, and the value is $8.43 \times 10^{5} \mathrm{~N} / \mathrm{m}^{3}$. The EMF density distributes uniformly on the involute part and is perpendicular to the surface.

The amplitude of EMF on rotor end windings is shown in Figure 4, and variations of radial, tangential, and axial components $(r, \varphi$ and $z$ ) of EMF are also presented. As rotor windings are interchangeable with each other, we present the change tendency for just one winding.

It can be seen that the amplitude of EMF on rotor end windings is about $0.4 \mathrm{kN}$, and its variation is periodic and the 


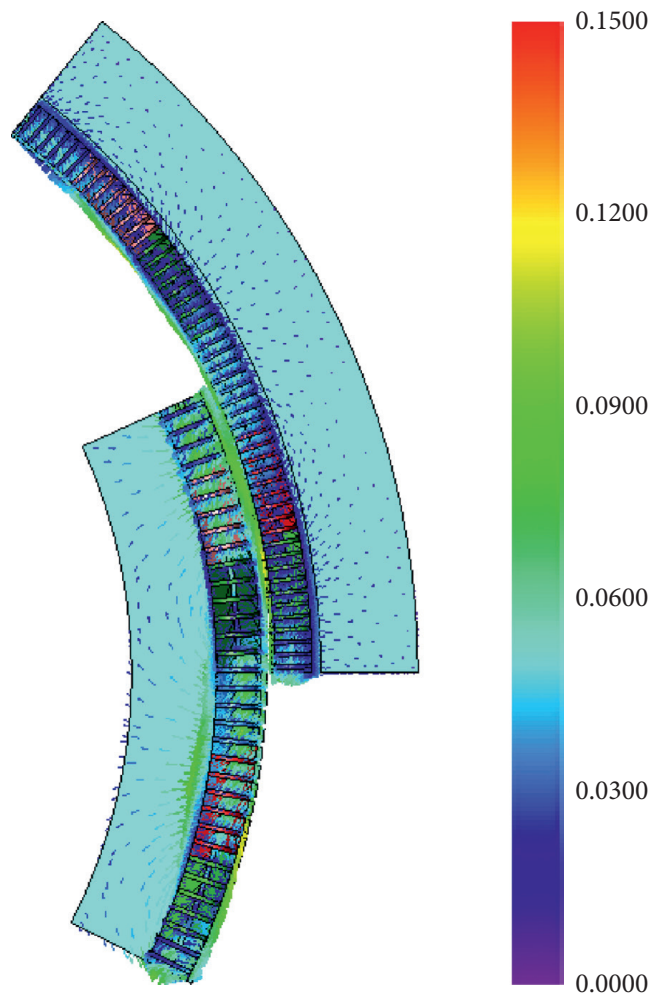

Figure 2: Distribution of flux density on the end region under rated load (unit: T).

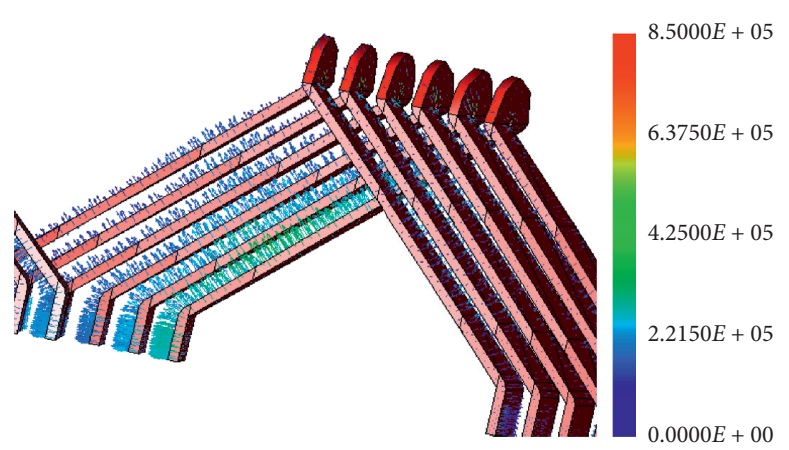

(a)

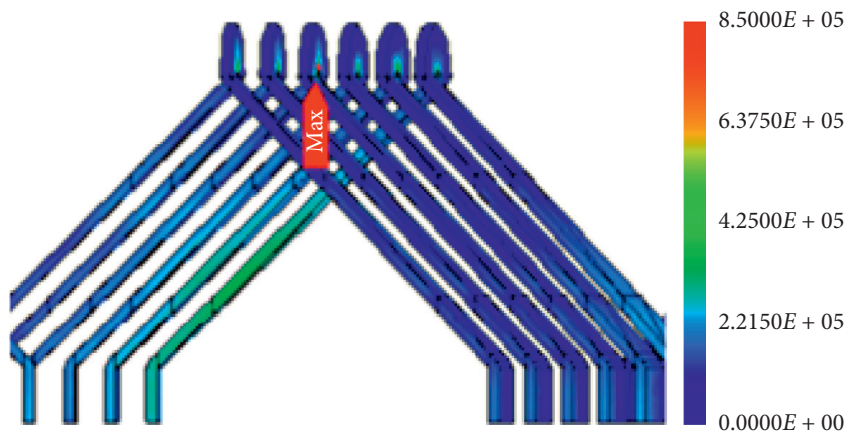

(b)

FIGURE 3: Distribution of EMF density on rotor end windings of $U$ phase (unit: N/m³). (a) Vector graph. (b) Nephogram.

frequency is 2 times of excitation frequency (the excitation frequency is $2.5 \mathrm{~Hz}$, and the frequency of EMF amplitude variation is $5 \mathrm{~Hz}$ ). Meanwhile, Figure 4 reflects the distribution of radial, tangential, and axial components of EMF. Peaks of three components are $0.39 \mathrm{kN}, 0.377 \mathrm{kN}$, and $0.144 \mathrm{kN}$, respectively. The radial and tangential components are larger than the axial components. Furthermore, according to Figures 4(b) and 4(c), when the radial component of EMF is the maximum, the tangential component is close to zero. The radial and tangential components vary without apparent periodicity.

2.3. At Supersynchronous Speed. Compared to the case with subsynchronous speed, there is no appreciable distinction about the amplitude of stator and rotor current at supersynchronous speed, except that the phase of rotor current is opposite. Therefore, only the amplitude of EMF on rotor end windings is presented in this case, as shown in Figure 5.

Figure 5 indicates that the amplitude of EMF on the rotor end windings is about $0.413 \mathrm{kN}$, which is larger slightly than the value in the case of sub synchronous speed shown in Figure 4, and its variation is periodic with frequency $5 \mathrm{~Hz}$.

\section{Analysis of EMF on Rotor End Windings under Three-Phase Short Circuit}

3.1. At Subsynchronous Speed. During short circuit, the current is much larger than rated current, leading to a higher 


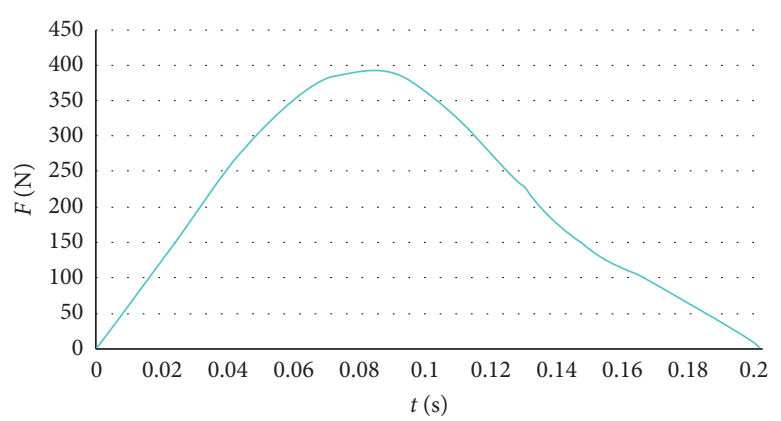

(a)

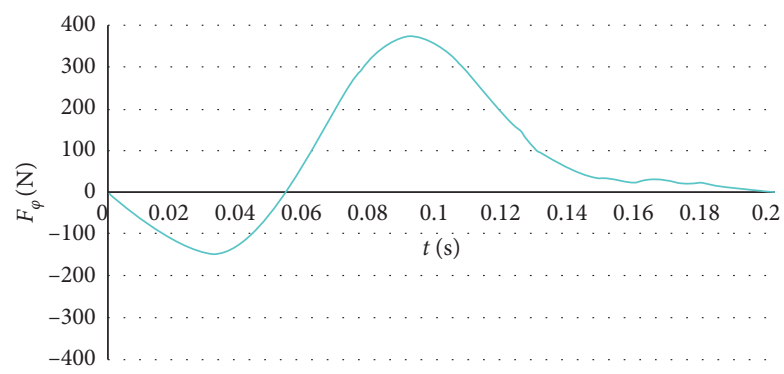

(c)

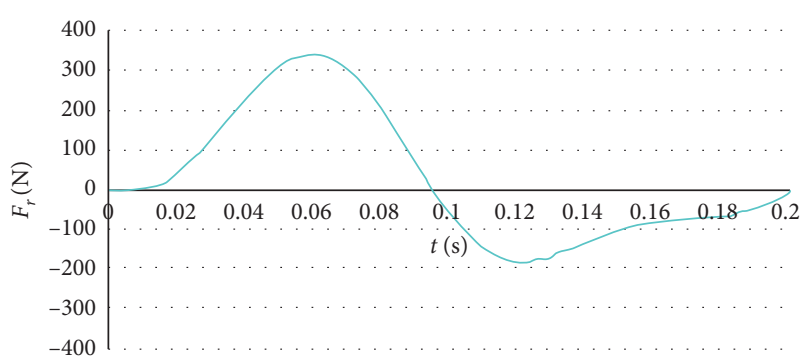

(b)

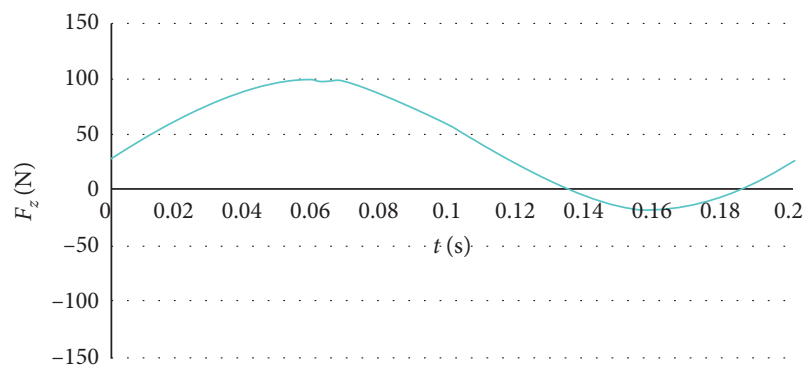

(d)

Figure 4: Amplitude and variation of EMF at subsynchronous speed. (a) The amplitude of EMF. (b) Variation of radial EMF. (c) Variation of tangential EMF. (d) Variation of axial EMF.

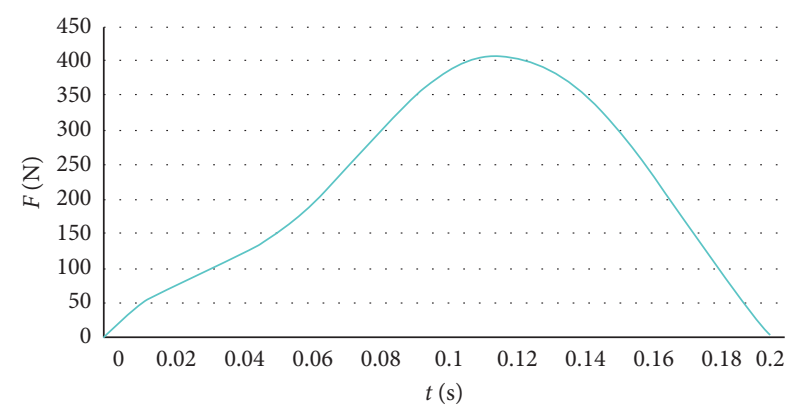

FIGURE 5: Amplitude of EMF at supersynchronous speed.

flux density, and the maximum value is up to $2.04 \mathrm{~T}$, as shown in Figure 6.

Figure 7 is the distribution of EMF density on rotor end windings of $U$ phase under short circuit.

It is shown that the maximum EMF density is still on the nose part of rotor end windings as presented in Figure 3, the value is $2.36 \times 10^{8} \mathrm{~N} / \mathrm{m}^{3}$, and the minimum value is $2.85 \times 10^{5} \mathrm{~N} / \mathrm{m}^{3}$. The distribution regularity of EMF density is the same as that obtained in the rated load case; however, the value is much larger, since the short-circuit current is very large.

The amplitude of EMF on rotor end windings is shown in Figure 8, and each curve shows the variation of EMF amplitude on each end winding.

Figure 8 indicates that the EMF on rotor end windings is increased greatly, compared to the EMF in rated load case, and the amplitude is up to $94.1 \mathrm{kN}$. The variation of EMF amplitude is periodic, and the frequency is $50 \mathrm{~Hz}$, which is different to the variation shown in Figure 4.
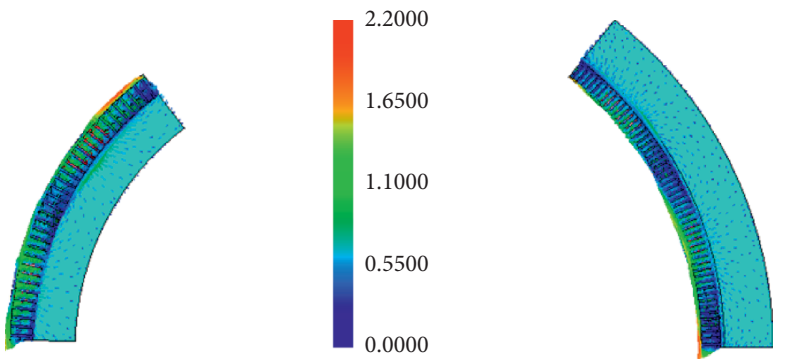

Figure 6: Distribution of flux density on the end region under short circuit (unit: T).

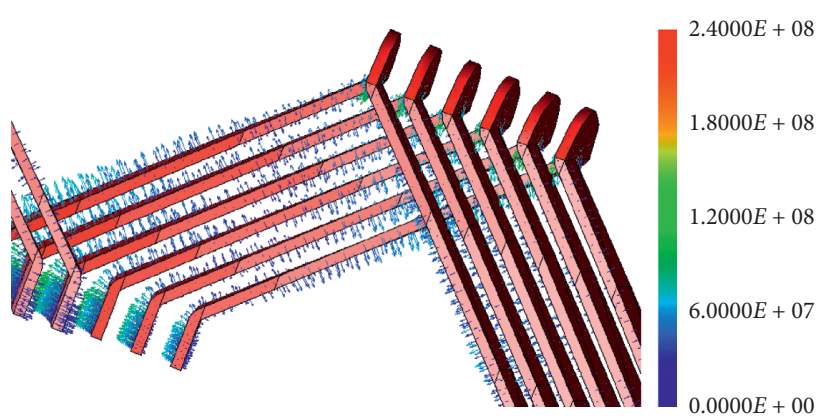

FIgURE 7: Distribution of EMF density on rotor end windings of $U$ phase (unit: $\mathrm{N} / \mathrm{m}^{3}$ ).

3.2. At Supersynchronous Speed. Figure 9 reflects the variation of EMF amplitude on rotor end windings at supersynchronous speed, in which each curve shows the variation of EMF amplitude on each end winding. 


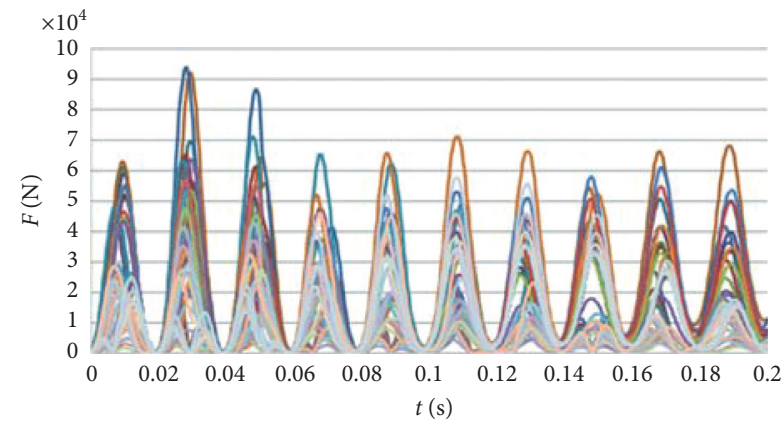

FIgURE 8: Amplitude of EMF under short circuit at subsynchronous speed.

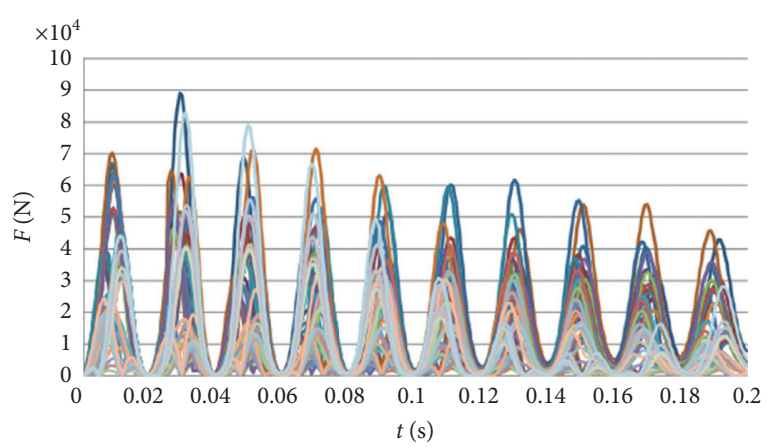

Figure 9: Amplitude of EMF under short circuit at supersynchronous speed.

The conclusion can be drawn from Figure 9 that the amplitude of EMF under short circuit at supersynchronous speed is about $89.1 \mathrm{kN}$, which is smaller than the value shown in Figure 8, and similarly, it varies periodically with frequency $50 \mathrm{~Hz}$.

According to Figures 4, 5, 8, and 9, the location with the maximum EMF is the nose part of rotor end windings. The EMF is much larger on short-circuit condition than that on rated case, as a very large short-circuit current. During rated condition, the variation of EMF is periodic and the frequency is 2 times that of excitation frequency, i.e., $5 \mathrm{~Hz}$, while during short-circuit condition, the frequency is $50 \mathrm{~Hz}$, which is the same as the power frequency.

\section{Conclusions}

The electromagnetic force on rotor end windings of a $300 \mathrm{MW}, 428.6 \pm 5 \% \mathrm{r} / \mathrm{min}$, variable-speed generator motor for pumped storage is investigated. Based on the $3 \mathrm{D}$ electromagnetic model of the end region, the distribution of EMF density and the variation of EMF amplitude and radial, tangential, and axial components $(r, \varphi$, and $z)$ are analyzed under rated load and three-phase short circuit at subsynchronous speed $(407.17 \mathrm{r} / \mathrm{min})$ and supersynchronous speed $(450.03 \mathrm{r} / \mathrm{min})$. It is concluded as follows:

(1) For all cases studied, the maximum EMF density is on the nose part of rotor end windings, and the EMF density distributes uniformly on the involute part and is perpendicular to the surface.

(2) During rated load, the amplitude of EMF is about $0.4 \mathrm{kN}$ at the subsynchronous speed and $0.413 \mathrm{kN}$ at the supersynchronous speed. The variation is periodic, and the frequency is 2 times that of excitation frequency (the excitation frequency is $2.5 \mathrm{~Hz}$, and the frequency of EMF amplitude variation is $5 \mathrm{~Hz}$ ).

(3) During three-phase short circuit, the amplitude of EMF is about $94.1 \mathrm{kN}$ at the subsynchronous speed and $89.1 \mathrm{kN}$ at the supersynchronous speed. The variation is periodic with frequency $50 \mathrm{~Hz}$.

(4) The EMF is one of the important constituents of force on rotor end windings, which may cause distortion, vibration, and even damage of rotor end windings. In order to avoid these problems and improve strength and stiffness of rotor end windings, some necessary measures, such as clamping bolt, U-type bolt, and end cap, must be taken. Conclusions drawn from this investigation will be beneficial for the material selection and structure design of rotor end windings and their support of large-scale VSGM.

\section{Data Availability}

The authors declare that the data are available by contacting through the following email: hec_sjsf43@163.com.

\section{Conflicts of Interest}

The authors declare that they have no conflicts of interest.

\section{References}

[1] T. Kubo, O. Osada, H. Tojo et al., Design and Manufacturing of the World's Largest 475 MVA/460 MW Adjustable Speed Generator-Motor for Pumped Storage Hydro Electric Power Plant, pp. 1-7, CIGRE, Paris, France, 2014.

[2] M. Johar, A. Radan, M. R. Miveh, and S. Mirsaeidi, "Comparison of DFIG and synchronous machine for storage hydropower generation," International Journal of Pure and Applied Sciences and Technology, vol. 7, no. 1, pp. 48-58, 2011.

[3] T. Kuwabara, A. Shibuya, H. Furuta, E. Kita, and K. Mitsuhashi, "Design and dynamic response characteristics of $400 \mathrm{MW}$ adjustable speed pumped storage unit for Ohkawachi Power Station," IEEE Transactions on Energy Conversion, vol. 11, no. 2, pp. 376-384, 1996.

[4] M. Valavi and A. Nysveen, "Variable-speed operation of hydropower plants: past, present, and future," in Proceedings of the XXII International Conference on Electrical Machines (ICEM), pp. 640-646, Lausanne, Switzerland, September 2016.

[5] D. Schafer and J. J. Simond, Adjustable Speed Asynchronous Machine in Hydro Power Plants and its Advantages for the Electric Grid Stability, CIGRE, Paris, France, 1998.

[6] J. Bendl, M. Chombt, and L. Schreier, "Adjustable-speed operation of doubly fed machines in pumped storage power plants," in Proceedings of the 9th International Conference on Electrical Machines and Drives, pp. 223-227, Canterbury, UK, September 1999. 
[7] G. D. Ciocan, O. Teller, and F. Czerwinski, "Variable speed pump-turbines technology," UPB Scientific Bulletin, Series D: Mechanical Engineering, vol. 74, no. 1, pp. 33-42, 2012.

[8] N. Richard, F. Duffeau, A. C. Leger, and N. Szylowicz, "Computation of forces and stresses on generator end windings using a 3D finite element method," IEEE Transactions on Magnetics, vol. 32, no. 2, pp. 1689-1692, 1996.

[9] N. Richard, "Calculation of electromagnetic forces on large generator end-windings under fault conditions using a threedimensional finite element method," Mathematics and Computers in Simulation, vol. 46, no. 3-4, pp. 257-263, 1998.

[10] K. C. Kim, H. W. Lee, Y. D. Chun, and J. Lee, "Analysis of electromagnetic force distribution on end winding for motor reliance," IEEE Transactions on Magnetics, vol. 41, no. 10, pp. 4072-4074, 2005.

[11] R. Lin and A. Arkkio, "3-D finite element analysis of magnetic forces on stator end-windings of an induction machine," IEEE Transactions on Magnetics, vol. 44, no. 11, pp. 4045-4048, 2008.

[12] R. Albanese, F. Calvano, G. Dal Mut et al., "Coupled three dimensional numerical calculation of forces and stresses on the end windings of large turbo generators via integral formulation," IEEE Transactions on Magnetics, vol. 48, no. 2, pp. 875-878, 2012.

[13] Y. Zhao, B. Yan, C. Zeng, S. Huang, C. Chen, and J. Deng, "Optimal scheme for structural design of large turbogenerator stator end winding," IEEE Transactions on Energy Conversion, vol. 31, no. 4, pp. 1423-1432, 2016.

[14] Y. Zhao, B. Yan, C. L Chen, J. A. Deng, and Q. W. Zhou, "Parametric study on dynamic characteristics of turbogenerator stator end winding," IEEE Transactions on Energy Conversion, vol. 29, no. 1, pp. 129-137, 2014.

[15] C. Zeng, S. Huang, Y. Yang, and G. Zhou, "Influence of end structure on electromagnetic forces on end winding of a 1550 MW nuclear generator," International Journal of Rotating Machinery, vol. 2017, Article ID 9545238, 12 pages, 2017.

[16] C. Zeng, S. Huang, and Y. M. Yang, "Analysis of electromagnetic forces on involute part of end winding in a 1550 MW nuclear generator," in Proceedings of the IEEE 2nd Advanced Information Technology, Electronic and Automation Control Conference, pp. 1-4, Chongqing, China, March 2017.

[17] H.-C. Jiang, Y.-L. He, G.-J. Tang, and M.-X. Xu, "A comprehensive analysis on transient electromagnetic force behavior of stator windings in turbo-generator," Mathematical Problems in Engineering, vol. 2018, Article ID 4189609, 16 pages, 2018. 